\title{
Case study - operation of three paste disposal facilities
}

\author{
R.A. Cooper Stefanutti Stocks Mining Services, South Africa \\ M.E. Smith Stefanutti Stocks Mining Services, South Africa
}

\begin{abstract}
The major advancement in the disposal of mine tailings over the past decade has been the generation, pumping and deposition of paste or thickened tailings. This has been brought about primarily to reduce water consumption at source but also to reduce other impacts on the environment. Stefanutti Stocks Mining Services operates three paste/thickened tailings facilities in South Africa; De Beers' combined treatment plant (CTP), De Beers' Voorspoed Mine and Assmang's Khumani Mine. The overall operating methodology for the three facilities is very different; however, the principles underpinning the operations are effectively similar. Several papers have been presented over the past few years regarding the operation of the CTP paste facility but few for the Voorspoed Mine facility and none for the Khumani Mine facility. This paper concentrates on the operational aspects of the three facilities providing an update on the CTP facility and describing the Voorspoed and Khumani Mine facilities. Challenges and successes with the facilities are described with the aim of providing guidelines for the design and operation of future paste facilities.
\end{abstract}

\section{Introduction}

Stefanutti Stocks Mining Services (previously Environmental, Civil and Mining Projects (Pty) Ltd or ECMP), A division of Stefanutti Stocks (Pty) Ltd, operates three thickened tailings disposal facilities in South Africa. These are:

1. De Beers Consolidated Mines - Kimberly Mines' Central Treatment Plant Fine Residue Deposit (CTP FRD).

2. De Beers Consolidated Mines - Voorspoed Mines Ultra Fine Disposal Facility (UFDF).

3. Assmang Limited - Khumani Iron Ore Mine Paste Disposal Facility.

Both the De Beers' facilities are kimberlite facilities while Assmang's is iron ore. Although each of the facilities were designed and are operated using different methodologies, there are a number of similarities that can be utilised as guidelines for the design and operation of future paste facilities.

This paper presents an overall description of the projects concentrating on the deposition facilities, summarises the deposition methodologies, describes the behaviour of the residue on deposition and discusses some of the challenges experienced and lessons learnt with the facilities.

\section{Overall description}

\subsection{De Beers combined treatment plant}

\subsubsection{Background}

De Beers Kimberly Mines commissioned the CTP to treat $100 \mathrm{Mt}$ of diamond bearing tailings in 2003. The tailings are scattered over many surface deposits around the city of Kimberly in the Northern Cape. These dumps are the waste product resulting from a century of mining diamonds.

\subsubsection{System description}

Five $15 \mathrm{~m}$ diameter deep cone thickeners were provided. The thickener underflow pumps discharge into a common paste transfer tank. The residue stream is pumped from the tank by three centrifugal charge pumps to three positive displacement piston diaphragm (PD) pumps. The PD pumps discharge via a manifold into a 
$5.5 \mathrm{~km}$ long $350 \mathrm{~mm} \mathrm{NB}$ high pressure steel pipeline to the deposition facility. Slurry densities are typically in the region of $1.6 \mathrm{t} / \mathrm{m}^{3}$ (60\% solids by mass).

\subsubsection{Disposal facility}

It was initially planned to deposit the fine tailings stream (paste) into worked out pits. If the pits were to be effectively filled, the tailings stream would need to be thickened into a paste thereby ensuring that the highest possible density would be achieved in the pit with maximum water recovery in the plant. The mining activities, however, still needed to be completed and a five year interim surface disposal facility was developed. The facility was constructed over an existing 390 ha tailings deposit that had been dormant for a number of years. Two vertical riser pipes were installed on the upper side of the tailings dam closest to the plant. The outer embankment was raised using compacted earth.

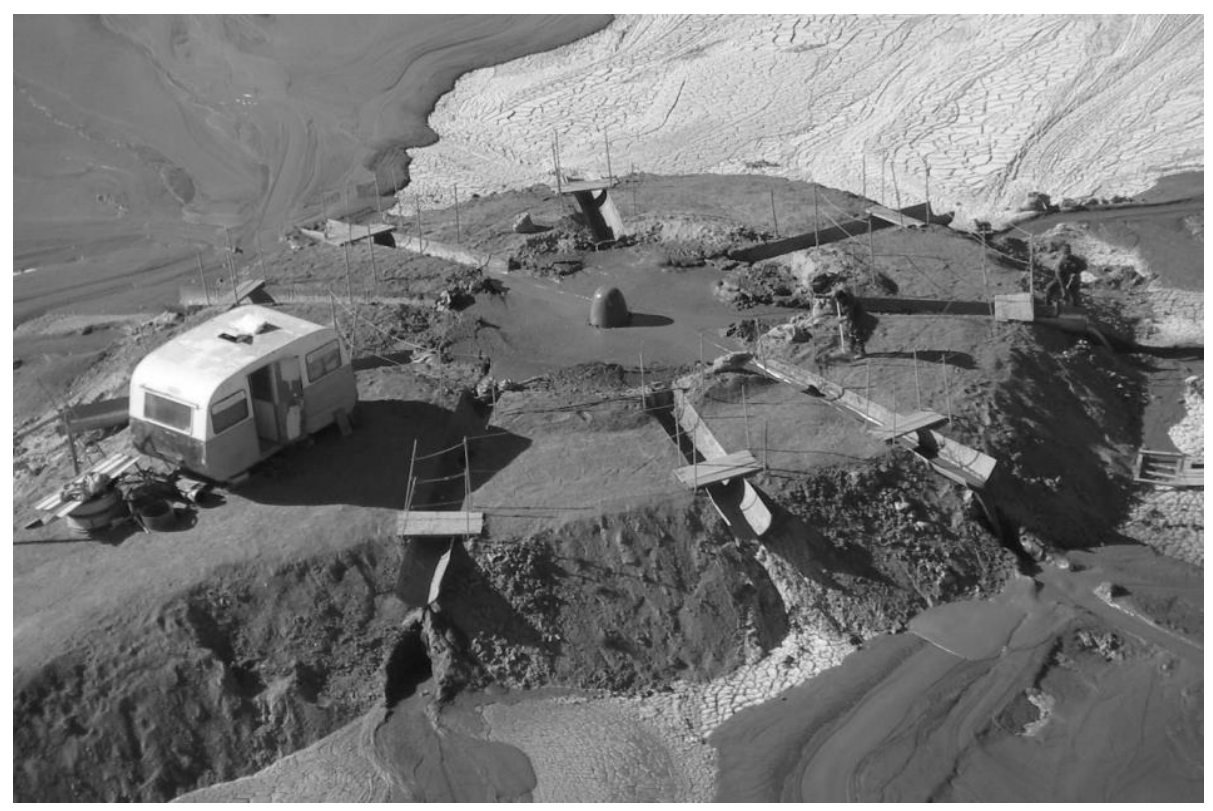

\section{Figure 1 CTP 'wagon wheel'}

Deposition is cycled between the two risers to allow the formation of an even beach as well as to allow the access roads to the towers to be raised mechanically. Deposition is cycled 360 degrees around each of the risers to control beach development and the location of the pool by means of the wagon wheel as shown in Figure 1.

Decant penstocks were installed at $300 \mathrm{~m}$ centres on the southern and south eastern walls to decant storm water off the facility.

\subsection{Voorspoed UFDF}

\subsubsection{Background}

De Beers' Voorspoed Diamond Mine is located approximately $30 \mathrm{~km}$ north east of Kroonstad. The mine was purchased by De Beers from Voorspoed Diamond Mining Company in 1912 and was officially re-opened on 4 November 2008.

Due to a shortage of water in the area, De Beers accepted that Voorspoed would thicken their tailings stream to maximise water return but at a maximum yield stress that could still be pumped using centrifugal pumps to reduce capital expenditure. 


\subsubsection{System description}

Two $18 \mathrm{~m}$ diameter high-rate thickeners are provided with a shear thinning loop to control the yield stress. The deposition facility is located relatively close (between 140 and 1,200 m) to the thickeners, assisting in the selection of the centrifugal pumps.

Tailings densities vary between 1.25 and $1.60 \mathrm{t} / \mathrm{m}^{3}$ with an average of $1.40 \mathrm{t} / \mathrm{m}^{3}$ (31-59\% solids by mass). The large variation in underflow densities is primarily due to the variable nature of the ore body. Different ore types settle differently and require varying quantities and types of flocculants and coagulants. In addition, the different ore types send instantaneous quantities of fines to the thickener making prediction of flocculent and coagulant requirements difficult.

\subsubsection{Disposal facility}

The facility was designed as an impoundment (compacted earth embankments) into which the tailings stream is deposited. Construction is phased with the facility being built as three compartments. All deposition is from one wall with the beach sloping towards the opposite wall. This main wall will eventually be central to the three compartments. The original design assumed a beach slope of 1(v):30(h) which was used to determine the height of the outer walls based on flume tests. Deposition is cycled between a series of openend deliveries to achieve an even beach and to control the pool position.

Supernatant water is removed by means of a decant penstock located in one corner of the facility. The water is decanted to a return water dam from where it is pumped to the plant for use in the treatment process.

\subsection{Khumani paste disposal facility}

\subsubsection{Background}

Khumani Mine is located near Kathu in the Northern Cape and was commissioned in 2007. The mine is currently constructing the Khumani Expansion Project (KEP) which will effectively double production.

Stefanutti Stocks Mining Services (SSMS) was awarded both Phase 1 and Phase 2 of the paste disposal facility by Assmang Limited as turnkey projects from prefeasibility through detailed design and construction to operation. This included the high rate thickener, all mechanical and electrical installations associated with the thickener, piping, the deposition facility and return water dams. SSMS's performance is measured by the percentage of water that is returned to the process plant for reuse.

\subsubsection{System description}

A primary conventional large diameter thickener was provided at the treatment plant. The thickener processes the tailings stream to a density in the region of $1.3 \mathrm{t} / \mathrm{m}^{3}$ (32\% solids by mass) to reduce the slurry volume being pumped from the plant to the disposal site. A secondary remote high rate thickener is provided approximately $6 \mathrm{~km}$ from the plant uphill of and adjacent to the deposition facility. The tailings stream from the primary thickener is then thickened to a density of $1.78-1.82 \mathrm{t} / \mathrm{m}^{3}$ (58-62\% solids by mass).

\subsubsection{Disposal facility}

Khumani Iron Ore Mine is an open pit operation and as such produces large quantities of overburden that can be utilised to construct the outer walls of the facility. The tailings dam has therefore been constructed as an impoundment with the outer wall formed by an engineered embankment constructed using waste rock or overburden in a phased process. The possibility of raising the wall with paste in the upstream direction in the final phase is still to be investigated.

The King Pit falls within the footprint of the tailings dam so that, once worked out, will add to the capacity of the facility. The basin has been divided into three compartments with engineered division walls to provide flexibility for the operations as well as to protect the King North Pit during the mining operations.

Barges have been provided in each of the compartments to pump storm water to the return water dams. This water is then pumped to the transfer tank at the paste plant and then flows by gravity to the process plant for re-use. 
Deposition behind the embankment is by means of a series of open-end deliveries off a ring feed located on the embankment. Deposition is cycled between deliveries to form an even beach and to maintain the pool position at the barge.

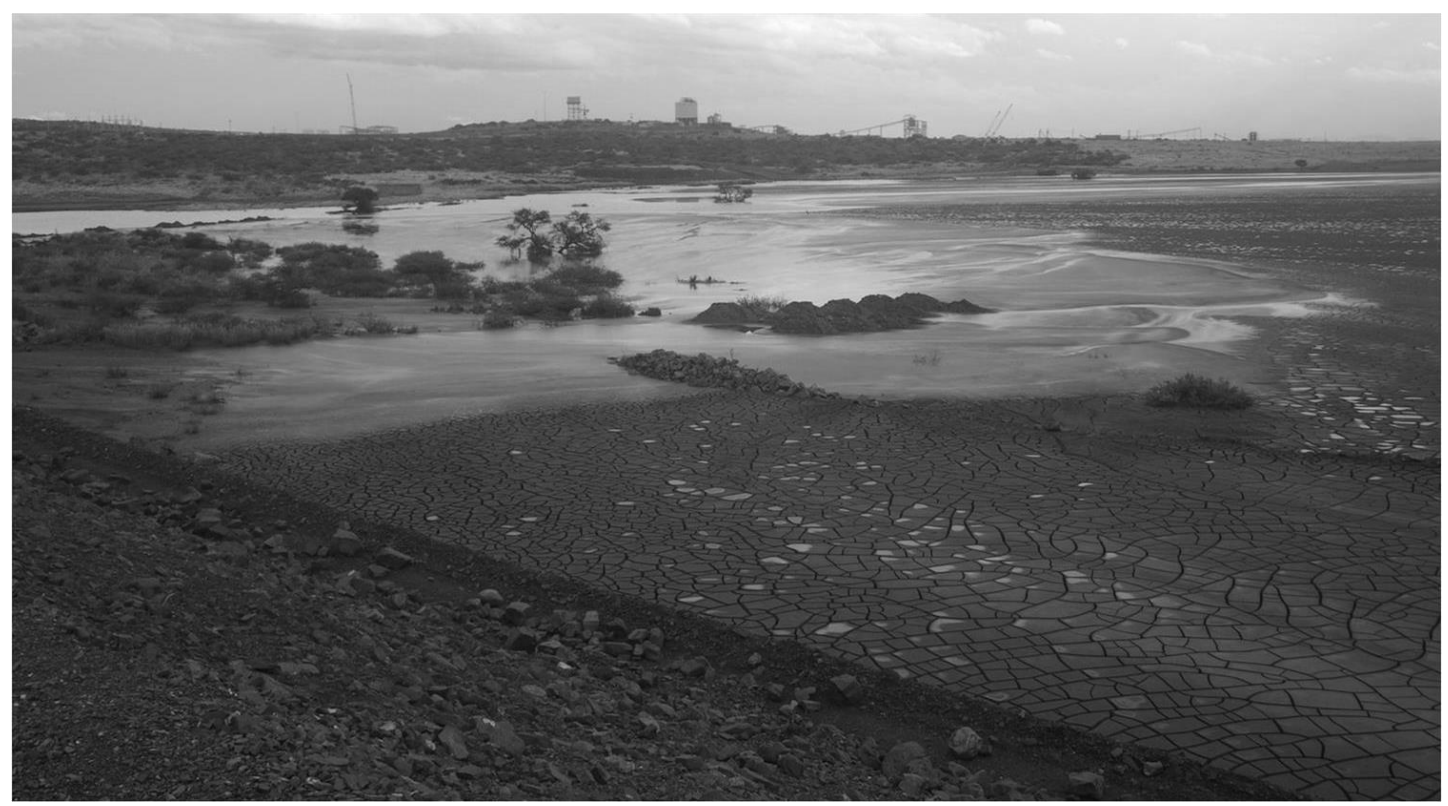

\section{Figure 2 Khumani TSF basin with the Phase 1 thickener in the background}

\section{Deposition behaviour}

There are a number of definitions of paste and thickened tailings in the industry, particularly when related to the thickening and pumping processes. From a deposition point of view, paste and thickened tailings are defined as being non-segregating and have limited or no bleed water on and post deposition. Paste is usually understood to require positive displacement pumps whilst thickened tailings can be pumped using centrifugal pumps. The terms are however, often interchanged and, for simplicity, in this paper the term paste includes both paste and thickened tailings.

The overall performance of a tailings facility is largely dependent on the behaviour of the tailings stream on deposition. The parameters defining the deposition characteristics need to remain relatively constant to ensure continuous satisfactory performance. This primarily includes:

- slurry density

- particle size distribution

- geotechnical parameters (strength and consolidation)

- chemistry.

In terms of the operations, the performance of the facility is described with regards to the operations in terms of beach profile and the distribution of tailings onto and around the facility.

\subsection{Beach profile}

Control over the position of the pool on a tailings facility is paramount to the successful operation of the facility. The majority of catastrophic failures (Bafokeng 12 lives; Merriespruit 17 lives; Stava 268 lives; Tashan 277 lives) have been due to overtopping of the outer wall by the pool. A facility utilising lower density tailings relies on segregation of the tailings stream on and post deposition to form a beach slope to develop a deeper area to store and contain process and storm water. This is particularly the case for a well graded tailings such as kimberlite.

Traditional kimberlite facilities utilising lower densities exploit this characteristic by depositing the tailings using multi discharge points known as spigots. The spigots reduce the velocity on deposition thereby 
maximising segregation such that the coarse fraction is deposited within the outer wall zone, the beach slope is maximised and the fine fraction is deposited towards the centre of facility at the pool position. In these facilities it is critical that the slurry density is maintained within a certain range. Densities below this range tend to cause the beach to be washed away whereas densities above this range tend to be non-segregating thereby forming a flat beach.

By definition, paste is non-segregating and instead relies on the yield stress of the paste to cause the paste to 'stack' thereby forming the beach slope. The slurry density however, still needs to remain above a specific density to maintain the beach slope. The yield stress at lower densities, although the tailings stream may still be non-segregating, is too low to allow the tailings to stack resulting in a flat beach.

In addition to pool control, the beach slope is also important to maximise the storage capacity of the facility. Too flat a beach will result in the outer walls having to be constructed higher to achieve the design capacity.

\subsection{Slurry distribution}

The distribution of slurry on the facility is a function of the flow pattern of the tailings stream on deposition which is largely dependent on the slurry density. A lower density slurry tends to flow as sheet flow and the operating methodology has to concentrate on restricting the flow by means of paddocks, trenches, cross walls, etc.

The flow of high density paste however, is typically in a lava-like pattern as shown in Figure 3 and is more difficult to predict and control.

\section{Challenges experienced}

\subsection{CTP paste facility}

\subsubsection{Riser operations}

Although flexibility was built into the design through the provision of two risers, no provision was made for valves to alternate deposition between the risers. Instead, deposition was controlled by means of blank flanges. This resulted in long periods of continuous deposition (3-6 months) from each riser due to the 18 hour downtime required to change risers.

This was rectified later by installing valves such that the change-over could occur whenever necessary with limited downtime of the plant.

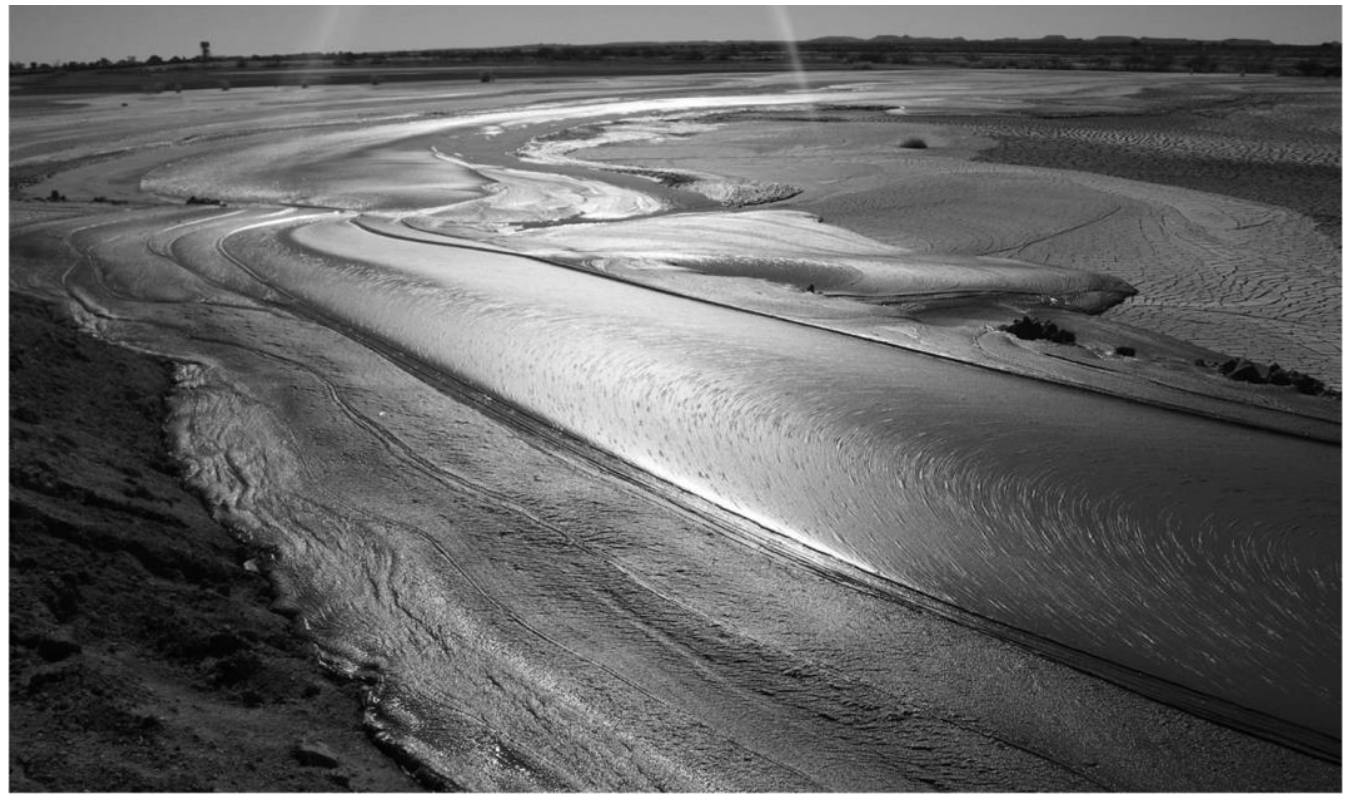

Figure 3 Lava-like flow of CTP paste 


\subsubsection{Lack of control over deposition}

The original design of the facility specified two vertical riser pipes in excess of $6 \mathrm{~m}$ high. The towers were seen as a zero maintenance item and no access was provided to the risers. This presented two problems; the momentum of the paste falling onto the base of the tower stopped the development of any beach and it was not possible to control the direction of the flow of the paste. The paste tended to flow below a surface crust making it impossible to predict where the paste would flow to and where the pool area would develop.

A number of alternatives were considered and tested to rectify the situation. The final accepted solution was the 'wagon wheel' concept as shown in Figure 1. The height of the tower was reduced to approximately $1 \mathrm{~m}$ high and eight launders were installed around the tower to form the spokes of the wagon wheel. Flow of the paste is controlled by using sand bags to block the launders.

Apart from being able to control the direction of flow, the wagon wheel also allows one to control the thickness of deposited layers. The flow is monitored constantly and when the flow starts to meander in the incorrect direction or if the thickness of the deposited layer is considered satisfactory the launders are changed. Ensuring that the deposition is in relatively thin layers enhances drying of the deposited paste as well as maximises the beach slope. The beach slope prior to conversion to the wagon wheel varied considerably but was in the order of $0.5 \%$. The beach slope is now more even and is currently approximately $1 \%$ and continues to increase gradually. It is not known at this stage where the beach slope will stabilise.

Cross walls were tried on the CTP paste facility to deflect the flow direction but these were functional only for a short periods as the area behind the cross wall tended to fill up quickly. Trenches are also used on the CTP paste facility to try control the flow direction particularly towards the northern flank. They are relatively successful but also tend to fill quickly.

\subsubsection{Raising of the outer wall}

As mentioned above, the CTP paste facility was only to be used for a period of five years after which deposition was to be into worked-out pits. The mining of the designated pits was however, not completed and the pits were sold. The facility is therefore now required to last for the remaining life of the mine with a predicted additional rise of $8 \mathrm{~m}$. The cost to raise the outer wall in the downstream direction using imported material was found to be prohibitive.

In order to reduce the volume of earthworks required for raising the wall, it was proposed that the wall be raised in the upstream direction. It was not known at that stage if the surface of the wall footprint would be suitable for forming a foundation for an upstream wall raise or if the surface would be trafficable by the equipment required to construct the wall. It was therefore decided to construct three trial embankments to determine the feasibility of the proposal.

The embankments were constructed in different sections of the facility to analyse trafficability of different founding conditions as shown in Figure 4. The trial embankments were $3 \mathrm{~m}$ high, had a $5 \mathrm{~m}$ wide crest and were $50 \mathrm{~m}$ long. The embankments were constructed in $300 \mathrm{~mm}$ layers and compacted to $80 \%$ Proctor density using a $14 \mathrm{t}$ vibratory smooth drum roller. Settlement indicators were installed at the base of the walls to determine the amount of settlement at the base of the wall during and after construction. The indicators comprised a flat $300 \mathrm{~mm}$ square plate connected to a steel round bar. Settlement was measured by surveying the top of the round bar.

Six sources of material were identified for raising the wall and were sent for laboratory testing. Based on these results, it was decided to use coarse CTP tailings, old fine tailings (slimes) and in situ CTP paste for the trials.

\subsubsection{Trial wall 1 -CTP tailings}

The original tailings dam was operated with a single deposition point in the northwest corner. This led to the fine fraction of the tailings stream being deposited against the southern wall. This fine material now forms the foundation for the upstream lifts, particularly on the southeast wall which was constructed across the tailings due to stability concerns of the outer wall. In addition, the rate of rise was particularly high in this area during initial uncontrolled deposition. It was therefore decided that a pioneer layer would be required for trial wall 1. Two options were utilised; waste rock and a layer of geofabric. Both options were shown to 
be adequate with the geofabric layer showing lower initial settlement. It was also found that a $300 \mathrm{~mm}$ layer of coarse tailings was sufficient to protect the geofabric from any damage. The CTP coarse tailings were found to compact well and the wall was considered competent.

\subsubsection{Trial wall 2 - old fine tailings}

A $300 \mathrm{~mm}$ box cut was initially excavated and the foundation compacted. A small upward bulge was observed in the base of the box cut. It was believed that this was due to the saturated state of the material below the box cut and the additional overburden pressures resulting from the excavated material being spoiled adjacent to the excavation.

The box cut was then filled with compacted coarse tailings. The wall was then raised using old fine tailings excavated from the northwest corner of the tailings dam near the original deposition point. Compaction of the material was difficult due to its fine grading and cohesionless nature. It was therefore decided to abandon this wall at a height of approximately $2.5 \mathrm{~m}$.

\subsubsection{Trial wall 3 - in situ CTP paste}

A box cut was initially excavated and backfilled with tailings. The upper $300 \mathrm{~mm}$ layer was then removed, placed and compacted in the wall in $300 \mathrm{~mm}$ layers. The paste below was too wet to be used in the wall and was therefore scarified and allowed to dry prior to being incorporated in the wall.

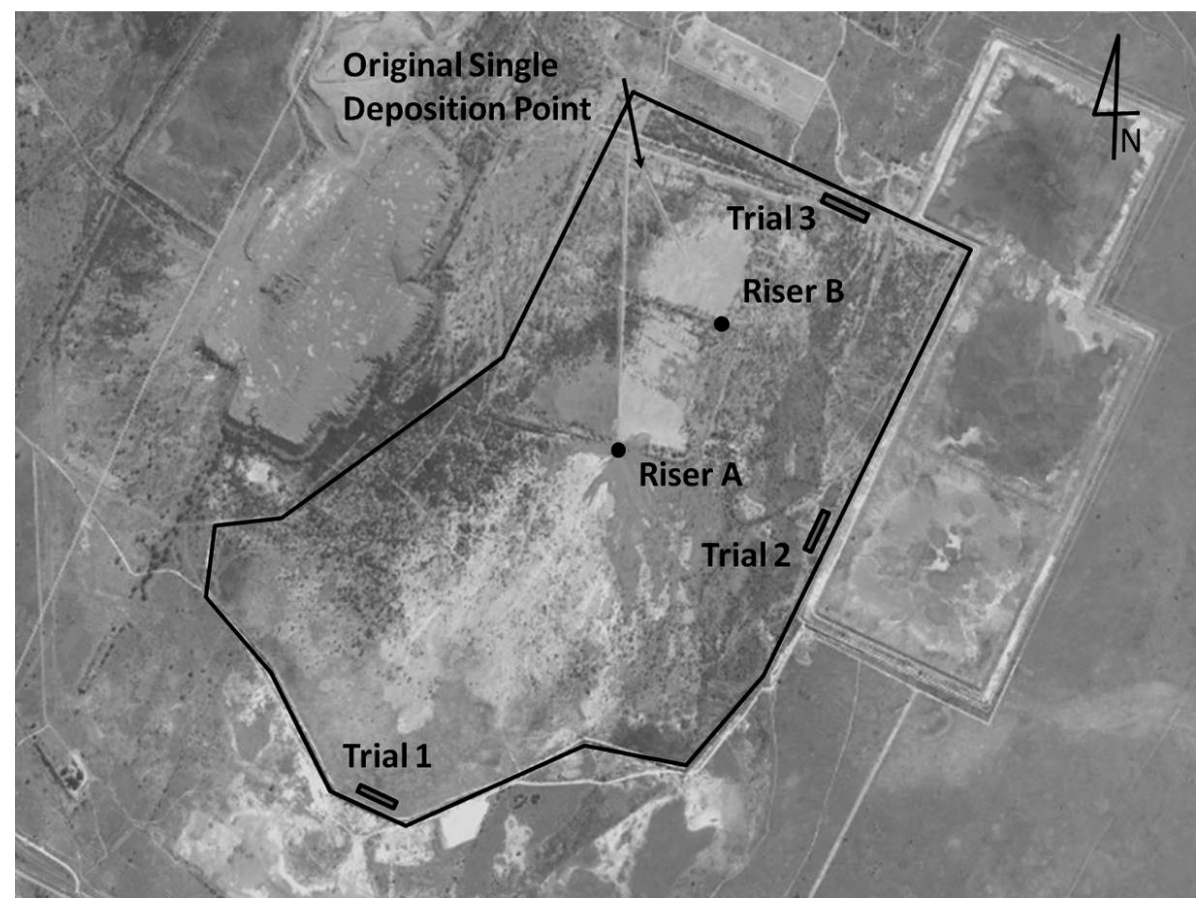

Figure 4 CTP paste facility (Google Earth, 2004)

\subsubsection{Summary of results}

The dried crust was found to be accessible by a $20 \mathrm{t}$ excavator for the majority of the facility. The only area of concern was the southeast flank where trial wall 1 was constructed. A pioneer layer proved essential in this area. The geofabric pioneer layer performed better than the waste rock in that settlement of the base was lower.

Significant cracking occurred on trial wall 1 within a few months of completion due to the poor founding conditions and lack of binding in the tailings. Cracking on the wall was less for the section constructed on geofabric.

The old slimes were not considered suitable due to issues with compaction, fines content and the cohesionless nature of the slimes. 
Constructing the wall using paste was considered successful as shown in Figure 5. The process was relatively slow due to having to wait for the paste to dry sufficiently. This is not considered a problem due to the length of wall that will be constructed in the future.

Subsequent to the testing, it was decided that the south wall, against which storm water lies, is to be constructed using selected borrow materials due to possible erosion of the wall. The wall will, however, still be constructed in the upstream direction.

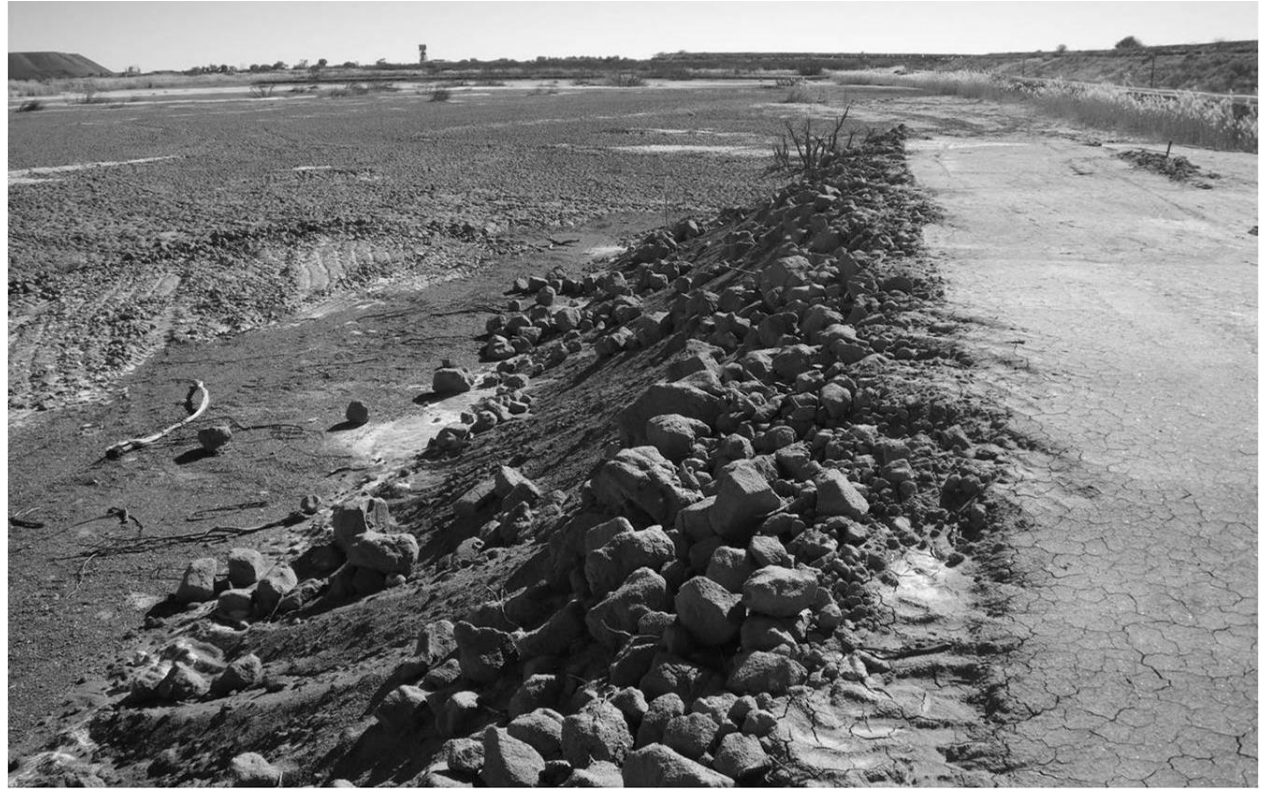

Figure 5 Trial embankment 3 constructed using in situ CTP paste

\subsection{Voorspoed UFDF}

\subsubsection{Slurry relative density and beach slope}

The ore body has been found to be highly variable which has complicated the operation of the thickener and, particularly during the early days, it was difficult to achieve the design slurry density as well as to keep the achieved density constant. This has led to the beach slope being significantly flatter (less than $0.5 \%$ ) than that predicted during the design phase (3.3\%), resulting in the outer walls having to be raised higher than the original design.

\subsubsection{Limited pool control}

The original design only allowed for single slurry delivery column on the main (south) wall. It was not possible to control the beach profile adequately and led to a pool being trapped in the corner opposite to the penstock. The delivery column was extended along the west wall for approximately two thirds the length of the wall. The extension was then used as required to deposit tailings along this flank to re-profile the beach towards the penstock.

\subsubsection{Penstock tower failure}

The decant system is comprised of a conventional penstock tower which is raised continuously using precast concrete rings to suit the level of the water and tailings. It is standard practice in conventional tailings dams to deposit material uniformly around the inlet to provide an equal support on all sides. In addition, when a pool wall is utilised to access the penstock, a launder is periodically cut into the pool wall to allow the coarse tailings fraction to be deposited at the intake to provide additional support. This is not possible at Voorspoed due to the configuration of the deposition system and location of the penstock. Tailings flow towards the penstock is only from one direction due to the single delivery column resulting in limited support to the tower due to the saturated state of the tailings surrounding the tower. A large mud rush caused by a failure of the beach slope pushed the tower over resulting in a failure of the penstock. The penstock was not repairable 
and a new penstock had to be installed. The resultant spillage through the outfall pipe was contained in the first $20 \mathrm{~m}$ length of the solution trench. The new penstock was provided with a supporting frame manufactured using standard scaffolding components.

\subsection{Khumani paste facility}

The Khumani paste facility has been extremely successful with no problems experienced on the tailings facility and a few minor problems on the thickening and pumping.

\subsubsection{Premature failure of bursting disks}

The delivery column consists of an initial 25 bar steel pipe from the thickener to the deposition facility and a 16 bar HDPE section on the main wall. Sixteen bar bursting disks were installed between the sections to protect the HDPE section from pressure surges. The disks were, however, not capable of withstanding sudden surges in the line and kept bursting. These were replaced with an HDPE pipe with a lower rating than the remainder of the line. This resolved the problem.

\subsubsection{Dedicated recirculation pumps}

The original system was designed such that the underflow pumps would be utilised for re-circulating the flow to control density. During situations when the bed level was rising and the densities were lowering, both the recirculation and discharge pipes need to be used which created difficulties in the operation. Dedicated re-circulating pumps were then installed to rectify the situation and to provide flexibility.

\section{$5 \quad$ Lessons learned}

\subsection{Deposition control}

All three of the facilities have shown that it is imperative that total control of the tailings stream is possible at all times, particularly in terms of the development of the beach profile, basin and layer thickness.

\subsection{Internal stability of the beach}

The majority of tailings dams in South Africa are constructed in the upstream direction with the outer walls formed by the tailings. The rate of rise of these facilities is a key factor in ensuring the stability of the outer walls as the rate of rise has to be below the rate of consolidation of the tailings to allow the wall to drain and gain sufficient strength to be self supporting.

The stability of impoundments in which the outer walls are constructed mechanically using selected borrow materials such as overburden is not related to the rate of rise and hence the rate of rise is often ignored except for when considering the life of the facility.

Both the CTP and Voorspoed facilities have however, demonstrated that the stability of the beach slope is dependent on the rate of rise. Prior to the introduction of the wagon wheel on the CTP facility, it was not possible to control the flow of the paste and this resulted in the south east flank of the facility rising by $6 \mathrm{~m}$ over a four month period. Although the usual crust developed, the material below remained saturated.

The Voorspoed penstock failure was caused by insufficient support around the tower and a mud rush from an internal failure of the beach slope. Higher slurry densities allowed the tailings to stack thereby steepening the beach slope. The high rate of rise of the facility however, meant that the submerged tailings are in an unconsolidated state and are incapable of providing a suitable foundation for the layers above. The upper layer would stack up to a slope which was unsustainable by the foundation and its own yield stress and would fail resulting in a mud rush towards the penstock intake. A number of these mud rushes were observed until a larger than normal rush pushed the penstock over. In addition to the framework provided for the new and future penstock towers, a diversion wall was constructed upstream of the tower to reduce the energy of any possible mud rushes. 


\subsection{Thickener control}

Stefanutti Stocks' battery limits at Khumani Mine are from the slurry discharge from the primary thickener to the discharge into the return water pipe line back to the plant. Appointing the contractor for the operation of both the thickener and the deposition facility has proven extremely successful due to:

- The thickener can be operated to suite the requirements of the tailings dam.

- Should any difficulties be experienced with the thickener or pumping system, the thickener can be bypassed whilst managing deposition of the low density tailings so as not to affect the performance of the deposition facility.

- The underflow pumping system can be bypassed whilst managing deposition in the bypass area thereby not affecting the performance of the deposition facility.

- The recirculation loop and dilution circuit can be operated as required to match the deposition requirements in terms of the location of the deposition point at the time and control over the beach profile.

\section{Conclusions}

The following can be concluded from the operation of the three facilities:

1. The deposition facility, pumping system and paste thickener need to be operated as an integral unit. The deposition facility poses the highest risk and generally requires the highest capital outlay and hence should dictate the system requirements rather than being at the end of the chain as is the usual practice.

2. Operating at the maximum density achievable by the thickener not only increases the operating cost but may under certain circumstances also increase the risk posed by the facility due to instability of the beach.

3. Including the operation of the paste thickener with the operation of the deposition facility has a significant advantage in that the requirements of the deposition facility in terms of slurry density can be matched as and when necessary whilst still maximising water recovery.

4. Control over deposition from the discharge onto the facility reduces the risk posed and makes for efficient usage of the available deposition capacity by creating a uniform beach and maximising the beach slope.

5. Although deposited at a higher initial density than conventional dams, deposition in thin layers to maximise drying remains essential to the safe development of the facility.

\section{Acknowledgements}

The authors would like to thank De Beers' Voorspoed Mine, De Beers' Kimberly Mines and Assmang's Khumani Mine for permission to publish this paper. 